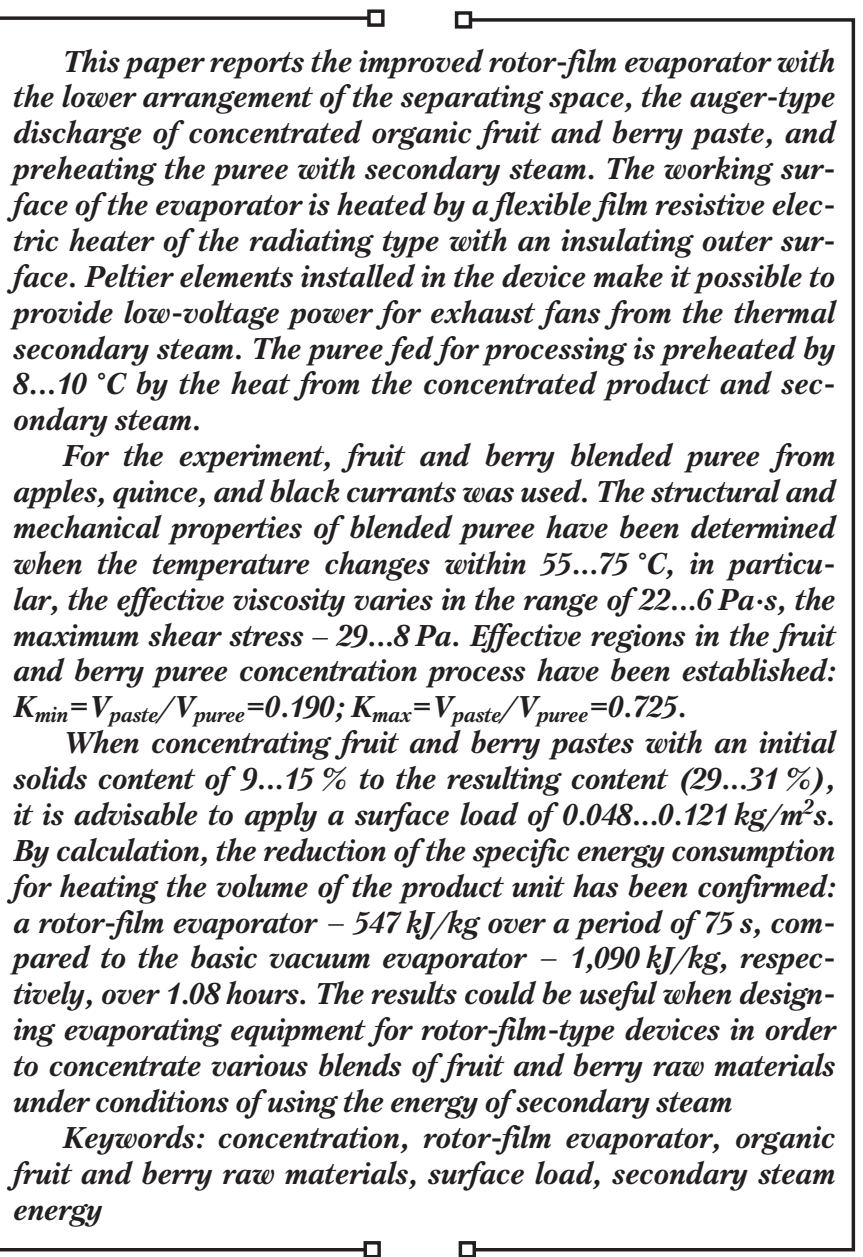

UDC 66.048.5.022.63:564.849

DOI $10.15587 / 1729-4061.2021 .237948$

\section{IMPROVED ROTARY FILM EVAPORATOR FOR CONCENTRATING ORGANIC FRUIT AND BERRY PUREE}

\author{
Andrii Zahorulko \\ Corresponding author \\ PhD, Associate Professor* \\ E-mail: zagorulkoAN@hduht.edu.ua \\ Aleksey Zagorulko \\ $\mathrm{PhD}$, Associate Professor* \\ Valeriy Mykhailov \\ Doctor of Technical Sciences, Professor* \\ EIdar I baiev \\ Postgraduate Student* \\ *Department of Processes and Equipment Food and \\ Kharkiv State University \\ of Food Technology and Trade \\ Klochkivska str., 333, Kharkiv, Ukraine, 61051
} Hospitality-Restaurant Industry named after M. Belaev
Received date 18.06.2021

Accepted date 04.08.2021

Published date 16.08.2021
How to Cite: Zahorulko, A., Zagorulko, A., Mykhailov, V., Ibaiev, E. (2021). Improved rotary film evaporator for concentrating organic fruit and berry puree. Eastern-European Journal of Enterprise Technologies, 4 (11 (112)), 92-98. doi: https://doi.org/10.15587/1729-4061.2021.237948

\section{Introduction}

Many countries around the world face the issue related to providing and expanding the range of functional and healthy food products employing modern innovative approaches in order to increase the resistance to chronic and infectious pandemic diseases, including COVID-19 [1]. The most common and effective ways to strengthen the immune system of the population are the formation of high-quality diets based on organic raw materials (berries, vegetables, fruits, spicy and aromatic raw materials, etc.) [2]. That, in turn, could reduce the use of artificial dyes, flavors, etc. with minimal benefit, in order to build a strong body immunity, which, to some extent, are cheaper compared to organic ones. Agro-industrial sectors today are aimed at cultivating organic raw materials, which require high-quality processing from harvesting to getting to the consumer, which is possible under the conditions of constant development of the production link. This confirms the feasibility of implementing resource-saving processes for the production of multicomponent organic semi-finished products for use in pure form or as part of recipes for food products with high nutritional value.

The resource efficiency of production processes depends on the degree of not only technological innovation but also equip- ment that implements the main operations, in particular during the processing of organic raw materials into multicomponent products; these include concentrating, drying, freezing, etc. [3]. The high-quality heat and mass exchange processes, in particular concentrating, requires the introduction of modern engineering and design solutions aimed at increasing resource efficiency, including through the use of secondary energy to reduce the duration of heat treatment. The high-quality implementation of concentration requires modern approaches when improving rotor-film evaporators under the conditions of implementation of resource-efficient technologies providing for a high-quality technological and structural approach to maximize the preservation of natural properties and high competitiveness of products. Therefore, it is a relevant task to introduce innovative engineering and technological solutions to improve rotor-film evaporators in the context of increasing the heat transfer coefficient and using secondary energy, ensuring the resource efficiency and competitiveness of the concentrated organic semi-finished products.

\section{Literature review and problem statement}

Works [4-6] focus on the need to promote healthy eating to increase innate immunity with the help of functional food 
semi-finished products and products that could minimize the damage caused by viruses to the health of nations worldwide. However, the impact of thermal processing modes on the quality and color of the food products received is not considered. Color is the first feature when choosing a product by the consumer, so papers $[7,8]$ pay attention not only to the organic component but also the physical and organoleptic properties of the products received on their basis since the consumer in most cases focuses on the appearance. But there are uncertain questions about the state and ways of intensification of the technical and hardware component of production, to justify the state of resource efficiency of production [9].That relates to one of the main factors, namely, the operational and technical condition of heat and mass exchange equipment, which quickly loses its structural and technological advantages compared to the pace of development of the technology industry since it has low resource efficiency. This explains the production need for innovative development of the technological and hardware component of the industry during the production of organic semi-finished products and food products based on them [10]. Improvement of the technological component of production is possible through the justified introduction of various blends of organic raw materials for obtaining a functional and healthy semi-finished product with the provision of expansion of the range of natural products and foods based on them. At the same time, the intensification of the technical component of the process requires the introduction of modern innovative solutions to ensure a high-quality process of concentrating organic raw materials in the context of the use of resource-efficient technologies when designing equipment, in particular, evaporators.

Paper [11] reports a study into the structure of a film evaporator resulting in the construction of a model for forecasting heat and mass exchange processes using thermaland hydrodynamic approaches to explore the interaction between the properties of the product and operational parameters. However, the issues regarding the received quality of concentrating processes depending on the techniques of heat supply and possible ways to increase the resource efficiency of the energy-intensive process remained unresolved. One solution is to study the influence of heat supply techniques during concentration, in particular, works [12,13] report an improved vacuum evaporator with electric heating of the working surface to produce high-quality fruit and vegetable pasty semi-finished products. However, the authors do not consider the issue of implementing comparative structural improvements in continuous-action devices, for example, rotor-type evaporators. Paper [14] shows the relationship between the effectiveness of heating when concentrating pomegranate juice depending on the amount of energy spent to achieve certain solids content (SC) in the semi-finished product and the heat transfer coefficient received. However, theoretical and practical data on the stages of determining the heat transfer coefficient under the conditions of concentration and ways of its intensification as one of the factors of the quality of the process remain unaddressed, thereby predetermining the need for research in this area.

Works $[15,16]$ report hydrodynamic studies of non-Newton liquids during heat and mass transfer treatment when stirring raw materials and indicate the need to build forecasting models to determine the technological and structural features of processes. That, in turn, could make it possible to form an idea of the course of the technological process of concentrating and save time on production tests. However, the issues of the impact of the duration of the processing of raw materials under the conditions of the possible use of secondary steam energy are not considered since the hydrodynamic models cannot fully determine ways to increase resource efficiency.

Papers [17, 18] are aimed at modeling the movement of flows, taking into consideration the peculiarities of heat transfer surfaces and profiles of the movement speeds of non-Newtonian liquids to determine the coefficient of heat supply depending on the energy spent. However, the possibility of changing the value of the heat exchange coefficient depending on the technique of heat supply and the degree of resource efficiency of the structures under study for concentrating has not been considered. The expediency of determining the increase in the coefficient of heat dissipation due to the introduction of resource-efficient technologies is explained, as most evaporators have a low coefficient of heat transfer, which leads to a decrease in the coefficient of resource efficiency and product quality. This approach confirms the importance of a set of studies aimed at determining the hydrodynamic and thermotechnical properties of the concentration process for the formation of generalized ways to ensure its resource efficiency.

Paper [19] provides information that the main feature of rotor-film evaporators is the practical absence of pressure drop for the height of the apparatus and a small volume of raw materials in it. That makes it possible to eliminate hydrostatic depression and reduce the duration of heat treatment; in most cases, devices with the upper arrangement of the separating space are used, from which the secondary steam enters the condensation. However, there are no data on the possible innovative approaches to increase the resource efficiency of evaporators, for example, when using secondary energy. One of the solutions to improve the efficiency of using secondary steam with maximum resource efficiency is to arrange a separating space in the lower part of the unit. At the same time, the subsequent transition of the separating space into a horizontal heat exchanger of the type "pipe in the pipe" could ensure the forced removal of secondary steam [20,21]. Such a structural solution would make it possible to arrange a coil heat exchanger in the "pipe in the pipe" assembly, ensuring the heating of the raw materials fed for concentration by the energy of secondary steam. However, in the cited works the possibility of applying such a structural solution in evaporators is not fully considered. Thus, there is a need for research to implement an appropriate design solution. The implementation of the concentration process requires a significant amount of energy for evaporation with the formation of a large amount of secondary energy, which is a source for various technological operations: heating, the autonomous operation of certain structural elements, etc. In practice, modern technologies for the conversion of secondary thermal energy are used, in particular, into low-voltage power through the use of Peltier elements; in this case, the received energy is used for further technological needs. Paper [22] reports the experimentally practical studies to confirm the effectiveness of using Peltier elements when using secondary energy (spent steam flux) to obtain low-voltage power for fans. However, no comparative characteristics to the evaporators of other structural solutions are given.

Taking into consideration the above confirms the relevance of implementation of various innovative solutions 
aimed at improving the resource efficiency of rotor-film evaporators to produce high-quality concentrated organic semi-finished products, which could expand the range of functional and healthy products. To some extent, the issues remain unresolved related to the possibility of the lower arrangement of the separating space in evaporators, the efficiency of using secondary energy in horizontal heat exchangers with the possibility of heating raw materials with secondary energy in them. Changing the steam heating system of rotor-film evaporators to modern electric heating with the help of a flexible film resistive electric heater of the radiating type (FFREhRT) [23] would ensure a decrease in metal consumption under the conditions of stabilization heating. Thus, the proposed solution of the rotary film evaporator leads to an increase in the heat transfer coefficient summarizing its resource efficiency in comparison with the basic designs of vacuum evaporators [24]. The results to be obtained would have a positive impact on the resulting resource efficiency of the energy-intensive process of concentrating organic raw materials, the quality of the products obtained, its competitiveness, thereby confirming the expediency of research in this area.

\section{The aim and objectives of the study}

The purpose of this work is to improve a rotor-film evaporator by arranging the bottom position of the separating space, the auger-type discharge of concentrated organic fruit and berry paste, and preheating the puree with the energy of secondary steam. Such a structural solution could improve the efficiency of RFE by reducing metal consumption, increasing resource efficiency when using the energy of secondary steam for heating the resulting puree, and the operation of exhaust fans.

To achieve the set aim, the following tasks have been solved:

- to design a model structure of the improved rotor-film evaporator with a bottom position of the separation space, the auger-type discharge of concentrated organic fruit and berry paste, and the preheating of the organic puree with secondary steam;

- to perform the experimental and estimation studies to confirm the effectiveness of the proposed structural and technological solutions in comparison with the basic design of the vacuum evaporator for concentrating an organic fruit and berry puree.

\section{The study materials and methods}

Our experimental and practical studies were carried out at the Research Center "Newest Biotechnology and Equipment for the Production of Food Products with High Health Properties", the Kharkiv State University of Nutrition and Trade (Ukraine).

The improved model structure of the rotor-film evaporator (RFE) (Fig. 1) with the bottom arrangement of the separation space, the auger-type discharge of concentrated organic fruit and berry paste makes it possible to detect ways to intensify heat and mass exchange processes. In addition, the proposed design and technological solutions make it possible to implement the technological process of preheating an organic fruit and berry puree directly within the RFE model using the energy of secondary steam.
The procedure for conducting the experimental study on determining the modes of RFE operation when concentrating organic fruit and berry puree involves a procedure for establishing a dependence between the degree of product distribution $K=V_{\text {paste }} / V_{\text {puree }}$, where $V_{\text {paste }}, V_{\text {puree }}$ are the volumes of the resulting fruit and berry paste and the resulting puree, respectively, and the main parameters affecting the process, the average temperature of the working surface $\left(t,{ }^{\circ} \mathrm{C}\right)$, vacuum $-p, \mathrm{kPa}$. We compared the characteristics of the rotor-film evaporator and a vacuum evaporator based on procedures for the thermal calculation of evaporators.

The following values of input parameters were used in the experiment: the average surface temperature, which transmits heat, is $\bar{t}_{1}=55^{\circ} \mathrm{C}, \quad \bar{t}_{2}=65^{\circ} \mathrm{C}, \quad \bar{t}_{3}=75^{\circ} \mathrm{C}$; pressure, $p=13 \ldots 15 \mathrm{kPa}$. The temperature of product feed is $t_{p r}=20 \ldots 25^{\circ} \mathrm{C}$. The rheological characteristics of the organic puree, depending on the temperature, were determined by the shear rate, $\gamma=2.7 \mathrm{~s}^{-1}$.

\section{Results of the experimental and estimation studies of the improved rotor-film evaporator}

\section{1. Building an improved model of the rotor-film evaporator}

The improved model of a rotor-film evaporator with a bottom separation space arrangement, the auger-type discharge of concentrated organic fruit and berry paste, and the pre-heating of organic puree with secondary steam is shown in Fig. 1. The upper part of the apparatus is vertical working chamber 1 , which is heated by a flexible film resistive electric heater of the radiating type with an insulating outer surface (FFREhRT) 2. That, in turn, would eliminate the steam component of the heat supply systems in standard evaporators and increase the structural resource efficiency.

The product enters the rotor-film evaporator through the nozzle injector of organic fruit and berry puree 3, located in the space of horizontal working chamber 4 , which is the structure of a tubular heat exchanger "pipe in the pipe". Injection nozzle 3 is connected to coil heat exchanger 5 , through the internal space of which the raw materials are pumped into device 6 (a hollow coupling) with rubber seals 7 . From coil 5 to vertical pipeline 8 , located in the internal space of rotating rotor 9 with hinged locks for fastening cutting blades 10 . Vertical pipeline 8 is connected to the cone-shaped distribution nozzle 11, thereby forming a thin-film layer of raw materials with subsequent heat and mass transfer treatment under an overpressure of $13 \ldots 15 \mathrm{kPa}$. RFE at the top is equipped with control and safety valves 12 , which additionally increases the safety of using the evaporator during vacuuming.

After forming a thin-film current with a cone-shaped distribution nozzle 11 and subsequent heat treatment by moving a layer of the raw materials by cutting blades 10 to the bottom of the apparatus. The concentrate enters by means of a narrowed lower part from the vertical working space to the horizontal one entering separation space 13 , forming, due to a sharp expansion of the separation space, the concentrate and the steam component (condensate). The concentrate, due to its physical properties, falls on auger 14, located in the inner space of horizontal heat exchanger 4, providing the thermal stabilization of the concentrate and the final removal of the steam-containing 
component after the heat treatment of the puree. From auger 14, the concentrated semi-finished product (organic paste), through nozzle 15, is discharged for further technological operations (packaging, drying, etc.).

The steam-containing component enters, from separation space 13, the intertube space of the horizontal heat exchanger "pipe in pipe" 4 with installed Peltier elements 16, thereby converting thermal energy into low-voltage power for exhaust fans 17 . We have experimentally established the formation of low-voltage power at the temperature of steam-containing flows above $35^{\circ} \mathrm{C}$. Fans 17 ensure the forced removal of steam-containing flows from separation space 4 to nozzle 18 , followed by their utilization for technological needs or discharge to the environment. Due to the forced movement of steam-containing flows between the tubular space of heat exchanger 4 with a coil heat exchanger 5 , its heating is ensured by $8 \ldots 10{ }^{\circ} \mathrm{C}$, thereby further improving the resource efficiency of the energy-intensive thermal process.

RFE is mounted on racks 19 , it has in the lower part equipment compartment 20 with a control unit over technological parameters (temperature in the main zones of heat treatment, pressure, rotation of rotor 9 and auger 14, etc.).

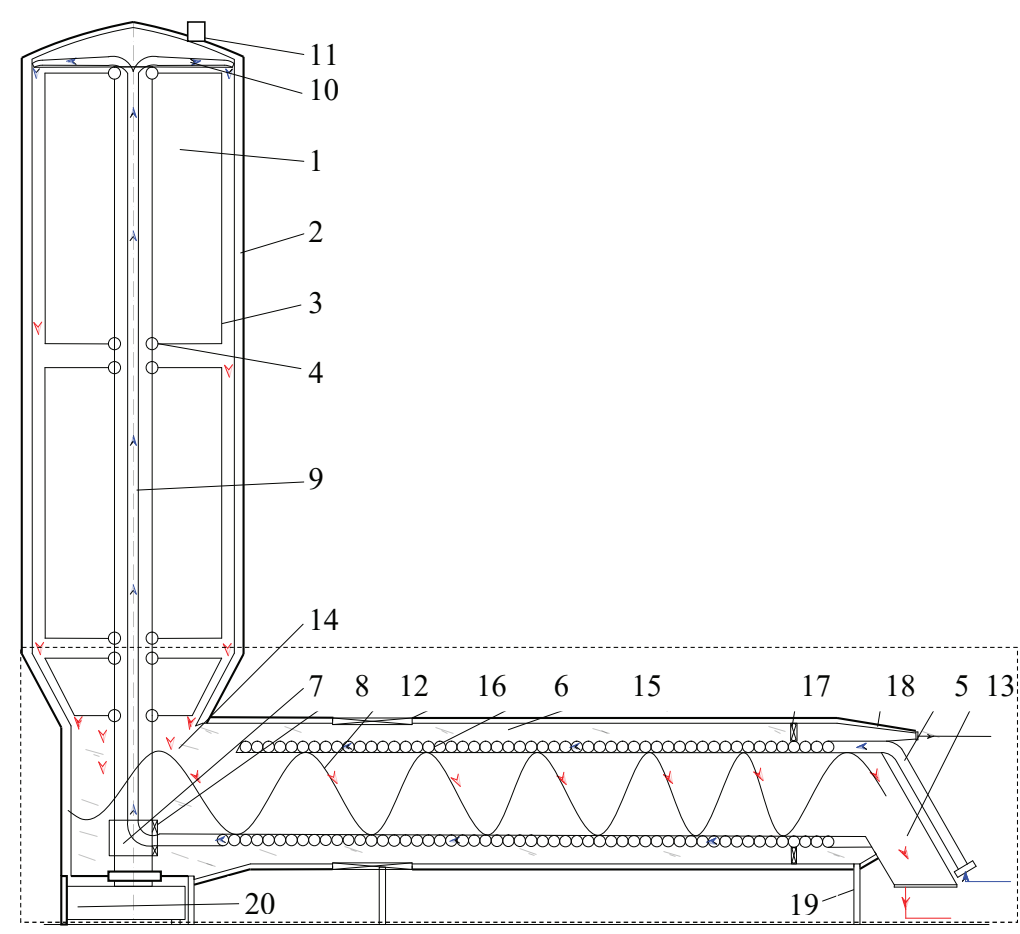

Fig. 1. Diagram of the improved model structure of the rotor-film evaporator with a bottom separation space arrangement, the auger-type discharge of concentrated organic fruit and berry paste, and the preheating of organic puree with secondary steam: 1 - vertical working camera; 2 - flexible film resistive electric heater of the radiating type with an insulating outer surface

(FFREhRT); 3 - injection nozzle for organic fruit and berry puree;

4 - horizontal working chamber (a heat exchanger pipe in the pipe); 5 - coil heat exchanger; 6 - puree intake device (hollow coupling); 7 - rubber seals; 8 - vertical pipeline; 9 - rotor with hinged clamps; 10 - cutting blades;

11 - cone-shaped distribution nozzle; 12 - control and safety valves;

13 - separation space; 14 - concentrate (paste) discharge auger;

15 - concentrate discharge nozzle; 16 - Peltier elements; 17 - exhaust

fans; 18 - secondary air discharge nozzle; 19 - racks; 20 - equipment department with a control unit over technological parameters
5. 2. The experimental and estimation studies into the impact of the proposed structural-technological ons on the process efficiency

We have performed an experimental study into the rocess of concentrating organic fruit and berry puree in in order to identify the main regime parameters and data for the further calculation of RFE. For quince, and black currants was used. The puree of apples, quince, and black currants was blended according to the formulations given in Table 1.

Table 1

Formulation compositions of organic fruit and berry puree and their structural-mechanical properties

\begin{tabular}{|c|c|c|c|}
\hline \multirow{2}{*}{$\begin{array}{l}\text { Component } \\
\text { composition }\end{array}$} & \multicolumn{3}{|c|}{ Formulation } \\
\hline & 1 & 2 & 3 \\
\hline Apple & 55 & 45 & 55 \\
\hline Quince & 30 & 45 & 40 \\
\hline Black currant & 15 & 10 & 5 \\
\hline \multicolumn{4}{|c|}{ Maximum shear stress, $\mathrm{q}_{0}$ : } \\
\hline $55^{\circ} \mathrm{C}$ & 29 & 25 & 22 \\
\hline $65^{\circ} \mathrm{C}$ & 23 & 17 & 13 \\
\hline $75^{\circ} \mathrm{C}$ & 15 & 12 & 8 \\
\hline \multicolumn{4}{|c|}{ Effective viscosity, $\eta_{e f}$. } \\
\hline $55^{\circ} \mathrm{C}$ & 22 & 18 & 16 \\
\hline $65^{\circ} \mathrm{C}$ & 14 & 10 & 8 \\
\hline $75^{\circ} \mathrm{C}$ & 11 & 8 & 6 \\
\hline \multicolumn{4}{|c|}{$\begin{array}{l}\text { Note: }{ }^{*} \text { - the structural and mechanical indicators } \\
\text { were determined at shear rate } \gamma=2.7 \mathrm{~s}^{-1} \text {, which cor- } \\
\text { responds to the mode of the organic puree flow in a } \\
\text { rotor-film evaporator }\end{array}$} \\
\hline
\end{tabular}

The data in Table 1 data indicate that when the temperature changes within $55 \ldots 75{ }^{\circ} \mathrm{C}$, the structural and mechanical properties of blended puree decrease. For the presented blends, with an increase in temperature, the effective viscosity varies in the range of $22 \ldots 6 \mathrm{~Pa} \cdot \mathrm{s}$, and the maximum shear stress - from 29...8 Pa. The results regarding the established structural-mechanical properties of organic puree have proven that the technologically required consistency of the resulting pastes can be ensured by selecting the rational composition of the initial components of plant origin, without the use of special thickeners. In addition, the structural-mechanical characteristics of the examined masses are used to calculate the hydromechanical and thermal processes.

The duration of concentrating in RFE is reduced by heating the fruit and berry puree entering for processing, and it depends on the design of the applied film-forming element. Taking into consideration the high pectin content in the product, we used a hinged blade in the experiment, equipped with an autonomous heating system for the reflective surface [25]. 
The derived dependences reflect complete information about the concentrating process (Fig. 2). At minimum consumption values $(W=0.15 \ldots 0.65 \mathrm{ml} / \mathrm{s})$, the operation of the unit is characterized by an underloaded mode with a minimum thickness of the product at the working surface, which leads to almost complete removal of moisture and burning of the product that sticks to the heat transfer surface. At elevated consumption values ( $W=1.9 \ldots 2.5 \mathrm{ml} / \mathrm{s}$ ), the product is heated but with a minimum degree of evaporation. A more stable removal of moisture from the fruit and berry puree occurs in the region $W=0.75 \ldots 1.85 \mathrm{ml} / \mathrm{s}$, where the maximum change in the speed of the initial parameter $K$ is observed.

The results of our study have made it possible to identify the region of the most effective RFE process during the concentration of fruit and berry puree. The effective region is within $K_{\min }=V_{\text {paste }} / V_{\text {puree }}=0.190 ; K_{\max }=$ $=V_{\text {paste }} / V_{\text {puree }}=0.725$. For concentrating fruit and berry puree in RFE from the initial content $S C=9 \ldots 15 \%$ to the resulting final solids content $=29 \ldots 31 \%$, it is advisable to apply a surface load of $0.048 \ldots 0.121 \mathrm{~kg} / \mathrm{m}^{2} \mathrm{~s}$. The relative error in measuring the degree of distribution $K(W)$ depends on errors in determining the consumption of the product and condensate, respectively, the heating temperature of the surface, and is $2 \ldots 3 \%$.

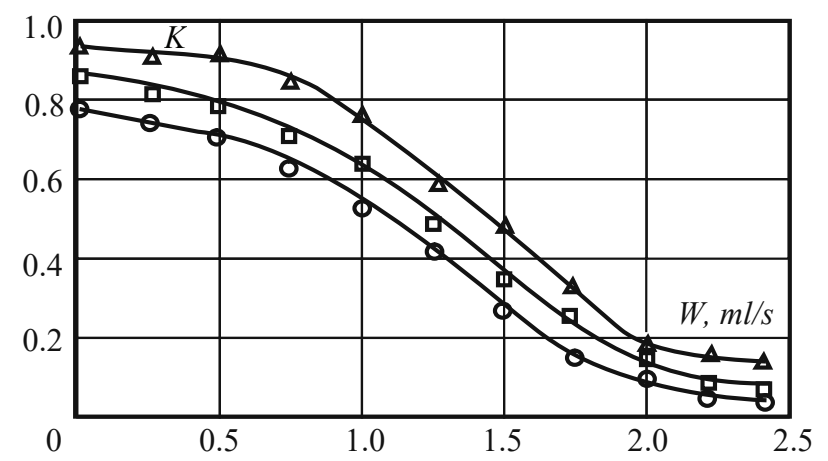

Fig. 2. Dependence of the distribution of product $K$ on the consumption of a fruit and berry puree at the temperature of the RFE working surface: $\Delta-55^{\circ} \mathrm{C}$; $\square-65^{\circ} \mathrm{C}$; $\circ-75^{\circ} \mathrm{C}$

Determining the efficiency of a rotor-film evaporator when concentrating a fruit and berry puree (Table 1, blend 2) from the final solids content of $14 \%$ to $30 \%$. The calculations were carried out without taking into consideration the loss to the environment (Table 2).
We have established a decrease by 2 times in one of the main indicators of resource efficiency - the specific energy consumption for heating the volume of the product unit: in RFE, $547 \mathrm{~kJ} / \mathrm{kg}$; basic VE, 1,090 kJ/kg, Table 2). This effect is explained by the smaller dimensional-weight characteristics of the RFE (the absence of steam heat networks) and a short-term intensive concentration of the product in a film flow, in contrast to the volumetric evaporation in the basic unit MZS-320. Reducing the duration of heat treatment: in RFE, $75 \mathrm{~s}$, and 1.08 hours (VE), providing for a lower temperature effect on the raw materials, and, therefore, the effectiveness of the implementation of our technological advancement in a technological line to produce organic fruit and berry semi-finished products.

\section{Discussion of results of concentrating an organic puree in the improved rotor-film evaporator}

Our experimental and practical studies confirm the effectiveness of using RFE when applying FFREhRT with the bottom location of the separation space, the auger-type discharge of concentrated organic fruit and berry paste, and the preheating of the puree with secondary steam (Fig.1). FFREhRT makes it possible to eliminate the steam heat supply system with an improvement in the energy efficiency of the process in general; the use of Peltier elements makes it possible to generate a low-voltage power to exhaust fans from the heat energy of secondary steam. The heat of the secondary steam and the concentrated product heats the puree, fed into the apparatus, by $8 \ldots 10{ }^{\circ} \mathrm{C}$, which further increases the resource efficiency of the process (Table 2).

The practical application of the proposed solutions would ensure a decrease in the inertia and metal consumption of the base evaporators by forming a uniform heat transfer surface and using secondary steam energy for heating the starting puree, providing for the autonomy of power supply to exhaust fans. There is an ensured increase in the resource efficiency, in particular, a decrease in the specific consumption of energy for heating the volume of the product unit: in RFE, $547 \mathrm{~kJ} / \mathrm{kg}$, over $75 \mathrm{~s}$, compared to the basic VE $-1,090 \mathrm{~kJ} / \mathrm{kg}$, over 1.08 hours (VE, Table 2). This is a characteristic difference between the proposed solutions from the existing ones since most studies on the concentration of plant raw materials are implemented by using metal-intensive steam shells and even with heating of the stirrer [26], which reduces the resource efficiency of the process and th resulting quality.

Table 2

Comparative characteristics of the rotor-film evaporator compared to a vacuum evaporator

\begin{tabular}{|c|c|c|}
\hline Indicator & Vacuum evaporator (MZS-320) & Rotor-film evaporator (RFE) \\
\hline Unit weight & $m^{*}=1,520 \mathrm{~kg}$ & $m=73 \mathrm{~kg}$ \\
\hline Unit heating & $\begin{array}{c}Q_{\text {heating }}=m_{1} c_{\mathrm{c}}\left(t_{4}-t_{3}\right)+m_{2} c_{\mathrm{c}}\left(t_{2}-t_{1}\right)=620 \cdot 0.48 \times \\
\times(143-80)+900 \cdot 0.48 \cdot(65-25)=18,748+17,280=36,028 \mathrm{~kJ}\end{array}$ & $Q_{\text {heating }}=m c_{\mathrm{c}}\left(t_{2}-t_{1}\right)=73 \cdot 0.48(65-25)=1,401 \mathrm{~kJ}$ \\
\hline To heat and boil product & $\begin{array}{c}Q_{p r}=m c\left(t_{k}-t_{n}\right)+r m_{\text {paste }}= \\
=1500 \cdot 3.7 \cdot(65-25)+2,350 \cdot 600=1,632,000 \mathrm{~kJ}\end{array}$ & $\begin{array}{l}Q_{p r}=G c\left(t_{k}-t_{n}\right)+r G_{\text {paste }}=3,700 \cdot 0.028(65-35)+ \\
\quad+2,350 \times 10^{3} \times 0.0052=15,328 \mathrm{~J} / \mathrm{s}(55,180 \mathrm{~kJ})\end{array}$ \\
\hline $\begin{array}{l}\text { Total amount of consumed } \\
\text { energy }\end{array}$ & $Q=1,635,608 \mathrm{~kJ}$ & $Q=56,581 \mathrm{~kJ}$ \\
\hline Specific consumption & $q_{p r}=Q / m=1,635,608 / 1,500=1,090 \mathrm{~kJ} / \mathrm{kg}$ & $q_{p r}=Q / G=15,328 / 0.028=547 \mathrm{~kJ} / \mathrm{kg}$ \\
\hline Treatment duration & $T_{M Z S}=Q / F \cdot k \cdot \Delta t=1,635,608 / 3.7 \cdot 1,454 \cdot 78=3,897 \mathrm{~s}$ & $T_{R F E}=L_{a n} / \mathrm{v}_{n l}=1.5 / 0.02=75 \mathrm{~s}$ \\
\hline
\end{tabular}

Note: * - Comparative data on the basic design of MZS-320 were adopted from a literary source [24] 
One of the limitations in the study of modes of concentrating fruit and berry puree is the stabilization of the temperature of the working surface when the consumption of the raw materials is changed. This issue can be resolved by precisely adjusting the volume of the raw materials for concentrating a fruit and berry puree with the help of an auger pump. Consumption of raw materials, in this case, is determined by a volumetric method. The RFE for concentrating a fruit and berry puree should be used at a surface load of $0.048 \ldots 0.121 \mathrm{~kg} / \mathrm{m} 2 \mathrm{~s}$ (Fig. 2), ensuring boiling efficiency. Further studies may be aimed at determining the heat transfer coefficient depending on the product consumption and the speed of rotor rotations according to the different thermophysical properties of products.

\section{Conclusions}

1. We have improved a rotor-film evaporator with the bottom separation space arrangement, the auger-type discharge of concentrated organic fruit and berry paste, and the pre-heating of the puree with secondary steam. The energy of the concentrated product and the secondary steam preheats the puree supplied to the apparatus by $8 \ldots 10^{\circ} \mathrm{C}$.
Heating the apparatus with a flexible film resistive electric heater of the radiating type with an insulating outer surface eliminates the steam component of heat supply systems.

2 . The structural-mechanical properties of blended puree have been determined when the temperature changes within $55 \ldots 75^{\circ} \mathrm{C}$, in particular, the effective viscosity varies in the range from $22 \ldots 6 \mathrm{~Pa} \cdot \mathrm{s}$, the maximum shear stress $-29 \ldots 8 \mathrm{~Pa}$. When concentrating fruit and berry pastes with an initial content $\mathrm{SC}=9 \ldots 15 \%$ to the resulting $\mathrm{SC}=29 \ldots 31 \%$, it is advisable to apply a surface load of $0.048 \ldots 0.121 \mathrm{~kg} / \mathrm{m}^{2} \mathrm{~s}$. By calculation, the reduction in the specific energy consumption for heating the volume of the product unit has been confirmed: in RFE, $547 \mathrm{~kJ} / \mathrm{kg}$, over $75 \mathrm{~s}$, compared to the basic VE, 1,090 kJ/kg, over 1.08 hours (VE).

\begin{tabular}{l}
\hline Acknowledgments \\
\hline This work was carried out in line with the State budget \\
theme No. 1-21 "Development of technological processes \\
and low-temperature equipment for the production of \\
multifunctional semi-finished products and confectionery \\
products using organic raw materials" under the guidance \\
of Associate Professor Andrey Zagorulko.
\end{tabular}

\section{References}

1. Galanakis, C. M., Rizou, M., Aldawoud, T. M. S., Ucak, I., Rowan, N. J. (2021). Innovations and technology disruptions in the food sector within the COVID-19 pandemic and post-lockdown era. Trends in Food Science \& Technology, 110, 193-200. doi: https://doi.org/10.1016/j.tifs.2021.02.002

2. Pap, N., Fidelis, M., Azevedo, L., do Carmo, M. A. V., Wang, D., Mocan, A. et. al. (2021). Berry polyphenols and human health: evidence of antioxidant, anti-inflammatory, microbiota modulation, and cell-protecting effects. Current Opinion in Food Science, 42, 167-186. doi: https://doi.org/10.1016/j.cofs.2021.06.003

3. Cherevko, A., Kiptelaya, L., Mikhaylov, V., Zagorulko, A., Zagorulko, A. (2015). Development of energy-efficient ir dryer for plant raw materials. Eastern-European Journal of Enterprise Technologies, 4 (8 (76)), 36-41. doi: https://doi.org/10.15587/1729-4061.2015.47777

4. Han, B., Hoang, B. X. (2020). Opinions on the current pandemic of COVID-19: Use functional food to boost our immune functions. Journal of Infection and Public Health, 13 (12), 1811-1817. doi: https://doi.org/10.1016/j.jiph.2020.08.014

5. Antine, S., L'Horset, A. M., Heiden, P., Salazar, G. (2020). Experiential children's nutrition education: Growing strong bodies and healthy minds. EXPLORE, 16 (5), 340-341. doi: https://doi.org/10.1016/j.explore.2020.06.007

6. Sucheta, Singla, G., Chaturvedi, K., Sandhu, P. P. (2020). Status and recent trends in fresh-cut fruits and vegetables. Fresh-Cut Fruits and Vegetables, 17-49. doi: https://doi.org/10.1016/b978-0-12-816184-5.00002-1

7. König, L. M., Renner, B. (2019). Boosting healthy food choices by meal colour variety: results from two experiments and a just-intime Ecological Momentary Intervention. BMC Public Health, 19 (1). doi: https://doi.org/10.1186/s12889-019-7306-z

8. Misra, N. N., Koubaa, M., Roohinejad, S., Juliano, P., Alpas, H., Inácio, R. S. et. al. (2017). Landmarks in the historical development of twenty first century food processing technologies. Food Research International, 97, 318-339. doi: https://doi.org/10.1016/j.foodres.2017.05.001

9. Cherevko, O., Mikhaylov, V., Zahorulko, A., Zagorulko, A., Gordienko, I. (2021). Development of a thermal-radiation single-drum roll dryer for concentrated food stuff. Eastern-European Journal of Enterprise Technologies, 1 (11 (109)), 25-32. doi: https://doi.org/ 10.15587/1729-4061.2021.224990

10. De Laurentiis, V., Corrado, S., Sala, S. (2018). Quantifying household waste of fresh fruit and vegetables in the EU. Waste Management, 77, 238-251. doi: https://doi.org/10.1016/j.wasman.2018.04.001

11. Silveira, A. C. P. (2015). Thermodynamic and hydrodynamic characterization of the vacuum evaporation process during concentration of dairy products in a falling film evaporator. Food and Nutrition. Agrocampus Ouest. NNT: 2015NSARB269. HAL. Available at: https://tel.archives-ouvertes.fr/tel-01342521/document

12. Cokgezme, O. F., Sabanci, S., Cevik, M., Yildiz, H., Icier, F. (2017). Performance analyses for evaporation of pomegranate juice in ohmic heating assisted vacuum system. Journal of Food Engineering, 207, 1-9. doi: https://doi.org/10.1016/j.jfoodeng.2017.03.015

13. AZahorulko, A., Zagorulko, A., Fedak, N., Sabadash, S., Kazakov, D., Kolodnenko, V. (2019). Improving a vacuum-evaporator with enlarged heat exchange surface for making fruit and vegetable semi-finished products. Eastern-European Journal of Enterprise Technologies, 6 (11 (102)), 6-13. doi: https://doi.org/10.15587/1729-4061.2019.178764

14. Ahmetović, E., Ibrić, N., Kravanja, Z., Grossmann, I. E., Maréchal, F., Čuček, L., Kermani, M. (2018). Simultaneous optimisation and heat integration of evaporation systems including mechanical vapour recompression and background process. Energy, 158, 1160-1191. doi: https://doi.org/10.1016/j.energy.2018.06.046 
15. Imran, A., Rana, M. A., Siddiqui, A. M. (2017). Study of a Eyring-Powell Fluid in a Scraped Surface Heat Exchanger. International Journal of Applied and Computational Mathematics, 4 (1). doi: https://doi.org/10.1007/s40819-017-0436-z

16. Acosta, C. A., Yanes, D., Bhalla, A., Guo, R., Finol, E. A., Frank, J. I. (2020). Numerical and experimental study of the glass-transition temperature of a non-Newtonian fluid in a dynamic scraped surface heat exchanger. International Journal of Heat and Mass Transfer, 152, 119525. doi: https://doi.org/10.1016/j.ijheatmasstransfer.2020.119525

17. Hernández-Parra, O. D., Plana-Fattori, A., Alvarez, G., Ndoye, F.-T., Benkhelifa, H., Flick, D. (2018). Modeling flow and heat transfer in a scraped surface heat exchanger during the production of sorbet. Journal of Food Engineering, 221, 54-69. doi: https://doi.org/10.1016/j.jfoodeng.2017.09.027

18. Crespí-Llorens, D., Vicente, P., Viedma, A. (2018). Experimental study of heat transfer to non-Newtonian fluids inside a scraped surface heat exchanger using a generalization method. International Journal of Heat and Mass Transfer, 118, 75-87. doi: https://doi.org/10.1016/j.ijheatmasstransfer.2017.10.115

19. Rotary film evaporators. Available at: https://hydropark.ru/equipment/film_evaporator.htm

20. Zahorulko, A., Zagorulko, A., Yancheva, M., Dromenko, O., Sashnova, M., Petrova, K. et. al. (2020). Improvement of the continuous "pipe in pipe" pasteurization unit. Eastern-European Journal of Enterprise Technologies, 4 (11 (106)), 70-75. doi: https://doi.org/10.15587/1729-4061.2020.208990

21. Morshed, W., Abbas, L., Nazha, H. (2021). Heating performance of the PVC earthair tubular heat exchanger applied to a greenhouse in the coastal area of west Syria: An experimental study. Thermal Science and Engineering Progress, 101000. doi: https://doi.org/10.1016/j.tsep.2021.101000

22. Liao, M., He, Z., Jiang, C., Fan, X., Li, Y., Qi, F. (2018). A three-dimensional model for thermoelectric generator and the influence of Peltier effect on the performance and heat transfer. Applied Thermal Engineering, 133, 493-500. doi: https://doi.org/10.1016/j.applthermaleng.2018.01.080

23. Zahorulko, A. M.,Zahorulko, O. Ye.(2016). Pat. No. 108041 UA. Hnuchkyi plivkovyi rezystyvnyi elektronahrivach vyprominiuiuchoho typu. No. u201600827; zaiavl. 02.02.2016; opubl. 24.06.2016, Bul. No. 12. Available at: http://uapatents.com/5-108041-gnuchkijjplivkovijj-rezistivnijj-elektronagrivach-viprominyuyuchogo-tipu.html

24. Vakuum-vyparnoy apparat MZS-320. Available at: https://www.mzko.com.ua/2015-08-03-00-59-07/vacuum-vyparnoy-apparat.html

25. Zahorulko, A., Zagorulko, A., Yancheva, M., Ponomarenko, N., Tesliuk, H., Silchenko, E. et. al. (2020). Increasing the efficiency of heat and mass exchange in an improved rotary film evaporator for concentration of fruit-and-berry puree. Eastern-European Journal of Enterprise Technologies, 6 (8 (108)), 32-38. doi: https://doi.org/10.15587/1729-4061.2020.218695

26. Cherevko, A., Mayak, O., Kostenko, S., Sardarov, A. (2019). Experimental and simulation modeling of the heat exchanche process while boiling vegetable juice. Prohresyvni tekhnika ta tekhnolohiyi kharchovykh vyrobnytstv restorannoho hospodarstva i torhivli, 1 (29), 75-85. 